\title{
Trichosporon asahii infection after total knee arthroplasty: A case report and review of the literature
}

\author{
Qiang Zuo MSc ${ }^{1,2 *}$, Lele Dong BD²*, Weidong Mu PhD ${ }^{1}$, Lingyun Zhou MSc ${ }^{3}$, \\ Tongping Hu MSc${ }^{4}$, Hua Zhang MSc ${ }^{5}$
}

\begin{abstract}
Q Zuo, L Dong, W Mu, L Zhou, T Hu, H Zhang. Trichosporon asahii infection after total knee arthroplasty: A case report and review of the literature. Can J Infect Dis Med Microbiol 2015;26(1):47-51.

Reports of fungal infection after total knee arthroplasty are extremely rare. In most reports, the infecting organism is a Candida species. The present report describes a case involving a 73-year-old immunocompetent woman who underwent total knee arthroplasty and presented one month later with signs of prosthetic infection. She underwent joint debridement and the fluid was sent for culture and sensitivity testing. The culture showed growth of Trichosporon asahii. The patient was administered intravenous and intra-articular injections of amphoteri$\operatorname{cin} \mathrm{B}$, followed by antifungal treatment with voriconazole for one year. At 26 months of follow-up, there was no evidence of infection and the patient was ambulating with a walker. To the authors' knowledge, the present case is the first report of $T$ asahii infection following knee replacement. Early detection, prompt institution of the appropriate antibiotics and regular follow-up are recommended.
\end{abstract}

Key Words: Fungal infection; Periprosthetic; Total knee arthroplasty; Trichosporon asahii

\section{L'infection à Trichosporon asahii après une arthroplastie totale du genou : un rapport de cas et une analyse bibliographique}

Les rapports d'infection fongique sont d'une extrême rareté après une arthroplastie totale du genou. Dans la plupart des rapports, l'organisme infectant fait partie des espèces à Candida. Le présent rapport décrit le cas d'une femme immunocompétente de 73 ans qui a subi une arthroplastie totale du genou et qui, un mois plus tard, a consulté en raison de signes d'infection prosthétique. Elle a subi un débridement articulaire, et le liquide a été envoyé pour mise en culture et test de sensibilité. La culture a révélé une croissance de Trichosporon asahii. La femme a reçu des injections intraveineuses et intra-articulaires d'amphotéricine $\mathrm{B}$, puis un traitement antifongique au voriconazole pendant un an. Après 26 mois de suivi, elle n'avait plus de traces d'infection et pouvait se déplacer avec un déambulateur. En autant que le sache les auteurs, ce cas est le premier rapport d'infection à $T$ asahii après une arthroplastie du genou. Ils recommandent le dépistage précoce, l'amorce rapide des antibiotiques pertinents et un suivi régulier.

\begin{abstract}
Tncidences of periprosthetic fungal infections following arthroplasty are extremely rare. In the few reported cases, Candida species were found to be the primary infecting organisms (1). Trichosporon asahii is widely present in the natural environment (2), and T asahii infection is more common in patients with immunodeficiency. $T$ asahii can infect the lung, skin, hair, lymph nodes or can present as a systemic disseminated infection. The present report describes a case involving primary total knee arthroplasty in a patient without immunodeficiency who presented with a postoperative $T$ asahii infection. A review of the literature on the treatment strategy for patients with postoperative fungal infections is also presented.
\end{abstract}

\section{CASE PRESENTATION}

A 73-year-old woman with bilateral osteoarthritis underwent bilateral single-stage total knee replacement. Routine preoperative and preanesthetic investigations were performed. She had a history of hypertension and type 1 diabetes mellitus, and was receiving appropriate medications. Her preoperative fasting blood sugar level was in the range of $6 \mathrm{mmol} / \mathrm{L}$ to $10 \mathrm{mmol} / \mathrm{L}$. She did not have a history of intra-articular injections of steroids or any other medications.
The bilateral knee replacement surgery was uneventful. Ceftezole (a first-generation cephalosporin) was administered before the skin incision as a preoperative prophylactic antibiotic. A tourniquet was used bilaterally. A midline skin incision was made and a medial parapatellar approach was used. The surgery lasted for $130 \mathrm{~min}$.

Her postoperative blood sugar levels were regularly monitored, and appropriate medications were administered. The volume of drainage from both knees was larger than usual for the first six days after the procedure. At day 6, the drainage volume was $<50 \mathrm{~mL}$ and, thus, the drainage tubes were removed. A wound inspection in the right knee revealed that although there was some evidence of superficial poor skin healing, the deep fascia had completely healed. In addition, the patient had a continuous low-grade postoperative fever $\left(37.3^{\circ} \mathrm{C}\right.$ to $\left.38^{\circ} \mathrm{C}\right)$. Laboratory examinations revealed a white blood cell count of $13.6 \times 10^{9} / \mathrm{L}$ and a neutrophil percentage of $85.6 \%$. For the first six days, she received a first-generation cephalosporin.

In view of the fever and findings of the wound check, the antibiotic was changed to imipenem/cilastatin sodium, which was given for an additional six days. A wound swab and right knee arthrocentesis culture results were normal at this time. The specimens were inoculated on

*Qiang Zuo and Lele Dong contributed equally to this work

${ }^{1}$ Department of Orthopedics, Provincial Hospital Affiliated to Shandong University, Jinan, Shandong Province; ${ }^{2}$ Department of Orthopedics, the First Affiliated Hospital of Baotou Medical College, Baotou, Inner Mongolia; ${ }^{3}$ International Education College, Jiang Xi University of Traditional Chinese Medicine, Nanchang, Jiangxi Province; ${ }^{4}$ Clinical Laboratory, the First Affiliated Hospital of Baotou Medical College; ${ }^{5}$ Department of

Oncology, the Third Affiliated Hospital of Inner Mongolia Medical College, Baotou, Inner Mongolia, People's Republic of China

Correspondence: Dr Weidong Mu, Department of Orthopedics, Provincial Hospital Affiliated to Shandong University,

No. 324, Jingwu Road, Jinan 250021, Shandong Province, People's Republic of China. Telephone 86-151-6886-3989,

fax 86-180-4721-1365, e-mail birchzq@gmail.com 


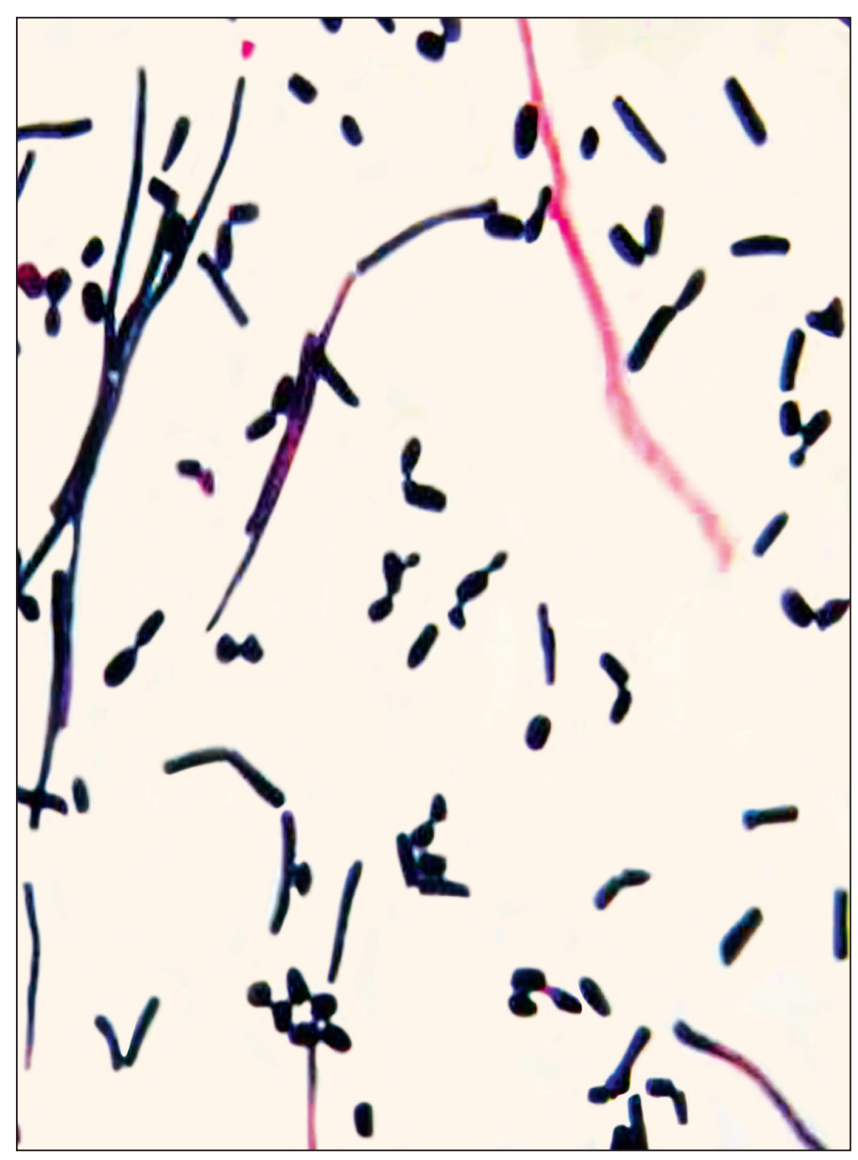

Figure 1) Colonies of Trichosporon asahii after $48 \mathrm{~h}$ on Columbia Blood agar at $35^{\circ} \mathrm{C}$ in ambient air. Morphological features of $\mathrm{T}$ asahii: $\mathrm{T}$ asahii is Gram-positive and produces blastoconida of various shapes, well-developed hyphae, pseudohyphae and arthroconida. (Gram stain, magnification $\times 1000$ )

Columbia Blood agar and China Blue Lactose agar at $35^{\circ} \mathrm{C}$ in ambient air and cultivated with a Bact/Alert3D Automated Blood Culture System (bioMérieux, France) for three days. Three weeks after surgery, the wound was debrided and resutured due to right knee wound dehiscence. Injectable vancomycin was administered for six days and, subsequently, the wound healed well. One month after the primary surgery, the patient presented with a persistent low-grade fever and recurrent pain on the right side of the left knee joint, which was accompanied by swelling. The temperature of the surrounding skin was also elevated.

Laboratory examinations revealed a normal blood cell count, C-reactive protein level of $27.2 \mathrm{mg} / \mathrm{L}$ (normal range $0 \mathrm{mg} / \mathrm{L}$ to $5 \mathrm{mg} / \mathrm{L}$ ) and erythrocyte sedimentation rate of $32 \mathrm{~mm} / \mathrm{h}$ (normal range $0 \mathrm{~mm} / \mathrm{h}$ to $15 \mathrm{~mm} / \mathrm{h}$ ). Arthrocentesis revealed that the aspirate from the left knee joint effusion was light yellowish in colour, while aspirate from the right knee effusion was pale, bloody fluid. Both were viscous, not muddy and cultures showed no bacterial growth.

Bilateral joint debridement and lavage was performed. During debridement, pus and necrotic tissue were not present, the synovial fluid was clear and transparent, the surface of the prosthesis was clean and smooth, all of the prosthetic components were stable without any loosening and the bone cement was fixed well. Synovium was completely resected and a pulse lavage system was used to ensure a thorough wash of the joint. In addition, the poly liners were changed. Five days after debridement, intraoperative sampling culture showed no bacterial growth in the right knee; however, the left knee joint fluid culture grew $T$ asahii (Figures 1 and 2). The cultures were grown on Columbia Blood agar and China Blue Lactose agar for $24 \mathrm{~h}$ to $48 \mathrm{~h}$. The API 20C

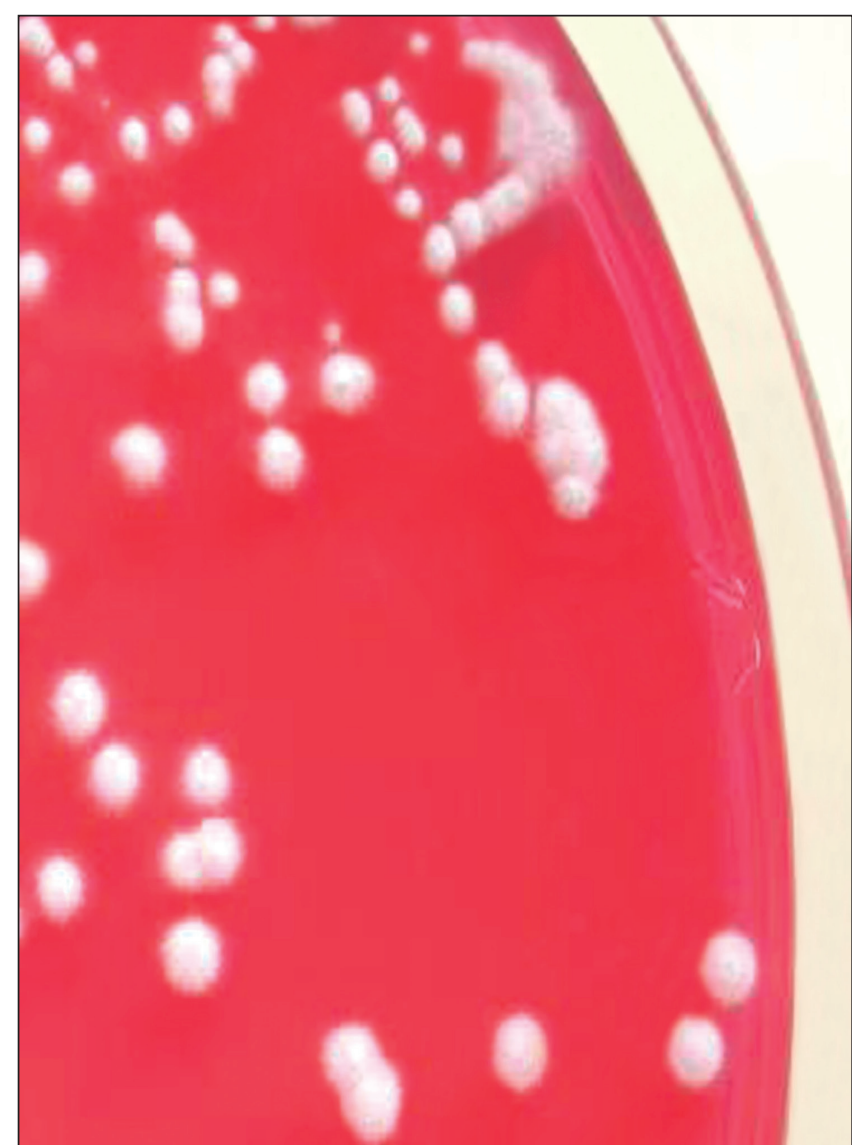

Figure 2) Colonies of Trichosporon asahii after $48 \mathrm{~h}$ on Columbia Blood Agar at $35^{\circ} \mathrm{C}$ in ambient air. Colonies were cream-coloured and smooth. They become dry, moist, shiny, folded, cerebriform and elevated with marginal zones with age

identification system (BioMérieux, France) was used to identify T asahii, which was sensitive to amphotericin $B$ and voriconazole. Intravenous amphotericin B (1 mg) was administered and increased to $5 \mathrm{mg}$ every subsequent day. However, due to the patient's worsening condition, on the third day, the amphotericin B dose was increased to $25 \mathrm{mg}$. The patient reported marked improvement in pain three days later. Due to the patient's poor appetite and persistent hypokalemia, the dosage of amphotericin B was not increased to the recommended maximum. Voriconazole alone was started after five weeks, and then after 10 days of intravenous therapy, the dose was changed to $200 \mathrm{mg}$ orally, twice per day. Intra-articular injections of amphotericin B ( $25 \mathrm{mg}$ once daily) were administered 17 days after surgery. Clinically, the patient continued to improve, her temperature stabilized (with occasional spikes of $37.5^{\circ} \mathrm{C}$ ) and the range of motion of the joint was $0^{\circ}$ to $90^{\circ}$.

The patient received oral voriconazole for one year. At the most recent follow-up, which was at 26 months following the primary procedure and 11 months after stopping all antibiotics, including oral voriconazole, the patient's general condition was good, body temperature was normal, function of the right knee had returned to normal, the left knee joint was mildly swollen (Figure 3), there was no joint effusion and the range of motion of the left knee was similar to the preoperative measure. However, there was pain on weight bearing and the patient required a cane for ambulation. Laboratory re-examinations revealed normal C-reactive protein level, erythrocyte sedimentation rate and routine blood tests, as well as liver and kidney function tests. X-rays showed that the prosthesis of the left knee was not loose, there was no evidence of osteolysis, and the prosthesis was well positioned (Figure 4). Laboratory tests and clinical manifestations revealed no drug toxicity and side effects. Left knee arthrocentesis repeatedly showed no growth of $T$ asahii. 


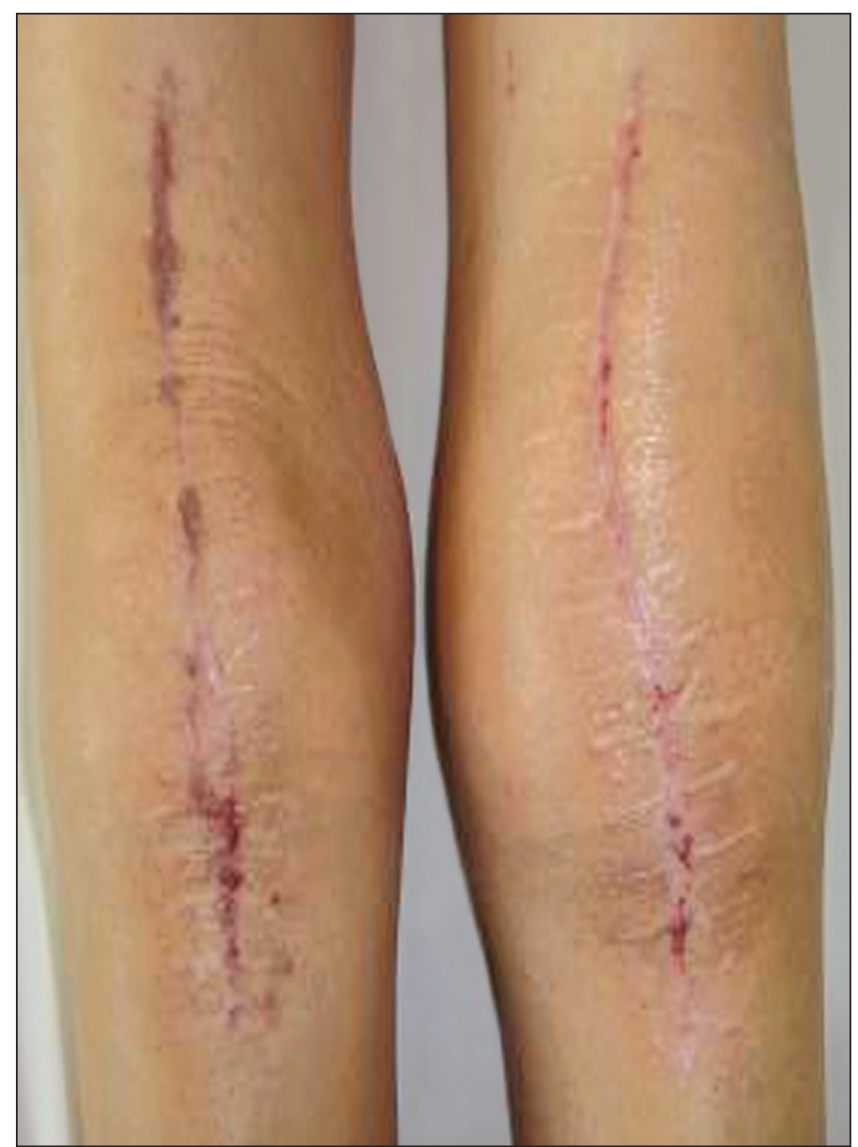

Figure 3) Gross morphology of the left knee 26 months after surgery. The left knee joint was mildly swollen

\section{DISCUSSION}

Periprosthetic fungal infection cases reported from 1979 to 2012 after artificial joint replacement totaled 57 reports, including 91 cases (3-59). Of these, there were 41 cases of hip replacements, 46 cases of total knee replacements, three cases of shoulder replacement and one case of metacarpophalangeal joint replacement. Candida albicans was the most commonly reported pathogen and was cultured in 38 cases. Candida parapsilosis was reported in 18 cases, Candida glabrata in 10 cases, Candida tropicalis in six cases, Aspergillus fumigatus in three cases, Pseudallescheria boydii in two cases, and one case of each of the following: Candida guillermondii, Aspergillus niger, Cryptococcus neoformans, Candida lipolytica, Phialemonium curvatum, Histoplasma capsulatum, zygomycosis, Syncephalastrum racemosum, Absidia corymbifera, Sporotrichum schenckii and Rhodotorula minuta. In addition, there was one case of coinfection by $\mathrm{C}$ parapsilosis and $\mathrm{C}$ albicans, and one case of coinfection by C glabrata and C albicans. The prostheses in 17 of the 91 patients were retained after antifungal therapy, of whom one had persistently painful knee reports during the follow-up, one needed continuous application of fluconazole (63 months), one had sinus tract persistence and three died (the cause of death was not related to joint diseases). Thirty of the 91 patients underwent two-staged reimplantation; swelling and pain during follow-up occurred in four, postoperative bacterial infection occurred in one (antibacterial treatment was successful), and there was one case of secondary infection after surgery (the patient died of heart failure). In addition, 28 of the 91 patients required prosthesis removal, of whom five needed continual treatment with fluconazole and four died. Finally, two of the 91 patients underwent successful single-staged replacement, while arthrodesis was performed in nine of the 91 patients and five of the 91 patients resulted in amputation.

$T$ asahii is widely present in the environment and is present in the normal flora of the human skin, gastrointestinal tract and respiratory

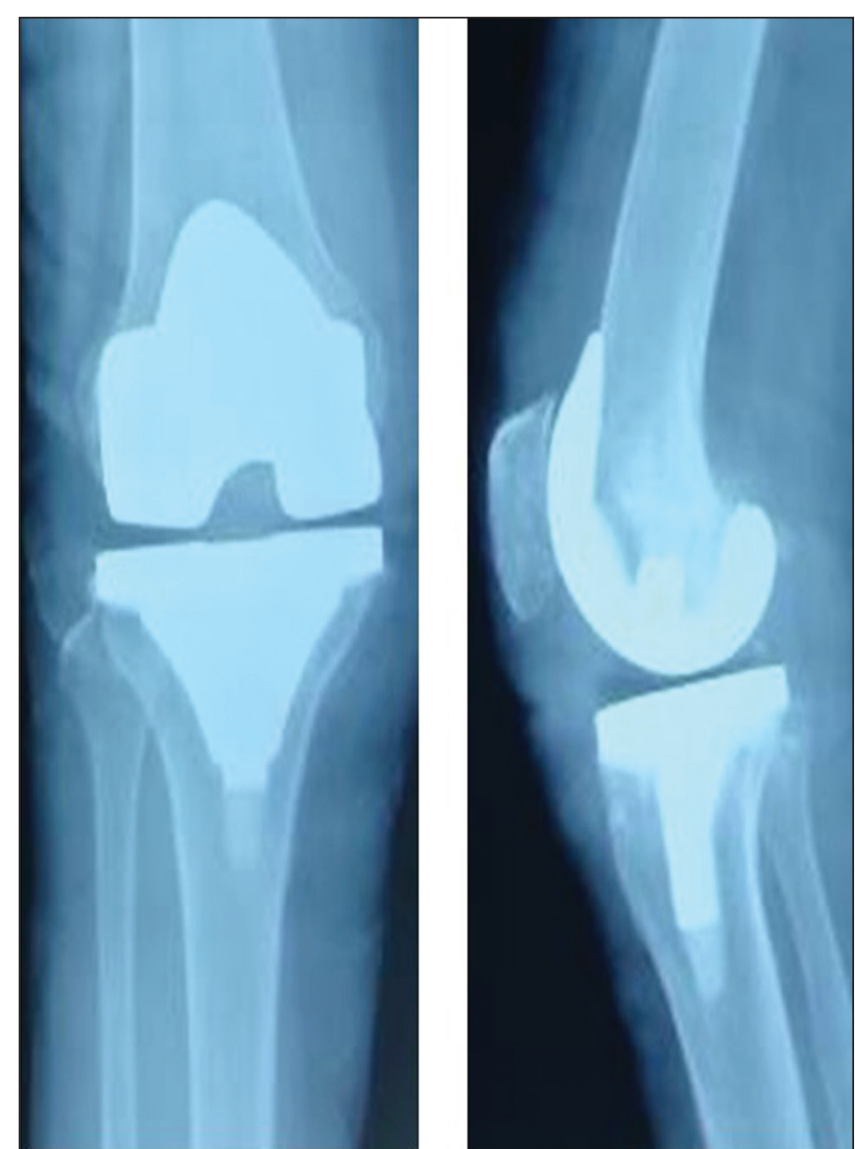

Figure 4) X-ray of the left knee 26 months after surgery. The prosthesis was not loose and there was no subsidence or migration

tract (60). Formation of biofilms on medical biomaterials in the hospital is very common. Studies have shown the presence of $T$ asahii in the wash basins in operating rooms (61). However, the overall incidence of $T$ asahii infection is low. As a conditional pathogen, it often causes a systemic disseminated infection in patients with transplantation, blood diseases, malignant tumours, immunodeficiency and leukopenia. The incidence of infection in nonimmunodeficient patients is rare, with only one case affecting the central nervous system and lung being reported in an immunocompetent individual (62). There are slightly more than 100 cases of disseminated infection caused by $T$ asahii reported worldwide (63). In previous reports, there were no reported cases of prosthesis infection with $T$ asahii after arthroplasty. $T$ asahii can easily lead to disseminated trichosporosis in particular populations; however, in the present case, blood cultures did not grow $T$ asahii, which may be due to the fact that the individual was immunocompetent.

Periprosthetic fungal infections are related to the use of glucocorticosteroids or immunosuppressants, or are observed in patients with malignant tumours. In addition, an increased risk for infection is related to excessive use of antibiotics for a prolonged period, indwelling catheters and patients in the intensive care unit. The patient in the present case underwent multiple surgeries due to postoperative fever and suspicion of bacterial infection. This particular patient may have been at risk for fungal infection due to prolonged use of antibiotics, the presence of indwelling catheters for long periods and multiple instances of recatheterization secondary to multiple surgeries.

Joint infections following arthroplasty are most often bacterial in origin. Because the overall incidence of fungal infection following arthroplasty is very low, microbiology experts and orthopedic surgeons may suspect contamination and incorrectly label the specimen as a 
false positive. It is difficult to detect fungal infections on pathogenic examination, and arthrocentesis often fails to reveal a positive fungal culture. In the present case, pathogens were not detected even after several synovial fluid cultures before debridement.

In the present case, detection of $T$ asahii was successful following debridement and immediate inoculation in blood culture media. Studies have shown that this sampling method can significantly improve the detection rate of specimens $(35,51)$. This method led to a prompt diagnosis, especially given the unexplained signs of infection. The present case report suggests that in cases in which the diagnosis is in doubt due to a confounding clinical picture, such as fever, pain and swelling of unknown origin, a fungal infection must be considered. Such cases warrant an extended culture time, specific culture conditions and a high degree of suspicion for the presence of rare microorganisms.

Common Candida infections are sensitive to amphotericin B and triazole drugs (fluconazole, itraconazole, voriconazole and posaconazole). $T$ asahii strains are sensitive to amphotericin $B$ and itraconazole (64). In addition, some reports indicate that $T$ asahii is highly sensitive to fluconazole and voriconazole in vitro (65); however, fluconazole resistance can occur. In the present case, susceptibility testing of the synovial fluid culture suggested resistance to fluconazole, itraconazole and 5-fluorocytosine; however, the patient was sensitive to amphotericin B and voriconazole. Therefore, it is important to select appropriate drugs and consider the resistance pattern.

Studies have suggested that biofilm formation of $T$ asahii is the main factor leading to persistent infection. $T$ asahii has a complex threedimensional structure under electron microscopy. Interestingly, relative to free cells, the resistance of $T$ asahii biofilm to voriconazole is 16,000 times greater (66), making it difficult to eradicate with voriconazole alone.

The efficacy of amphotericin B treatment of Candida and other fungal infections is well established. However, its renal toxicity can lead to sustained hypokalemia, nausea, vomiting and other side effects. Therefore, the dose is significantly limited in such patients. In the present case, because the application of amphotericin B led to sustained hypokalemia, we administered local intra-articular injections of amphotericin B to increase the local drug concentration. The joint swelling increased after intra-articular injection, but there was no local erythema or rash $24 \mathrm{~h}$ after injection. In addition, the patient's skin temperature decreased, the patient reported pain relief and her joint swelling subsided after one week.

As recommended by the Infectious Diseases Society of America, the appropriate time of antifungal treatment for Candida arthritis is between six and 12 months (67). In the present case, the patient was treated with antifungal voriconazole for one year. Symptoms did not reappear after withdrawal of the medication, even after 11 months.

\section{REFERENCES}

1. Azzam K, Parvizi J, Jungkind D, et al. Microbiological, clinical, and surgical features of fungal prosthetic joint infections:

A multi-institutional experience. J Bone Joint Surg Am 2009;91:142-9.

2. Sugita T, Nishikawa A, Ichikawa T, et al. Isolation of Trichosporon asahii from environmental materials. Med Mycol 2000;38:27-30.

3. Yilmaz M, Mete B, Ozaras R, et al. Aspergillus fumigatus infection as a delayed manifestation of prosthetic knee arthroplasty and a review of the literature. Scand J Infect Dis 2011;43:573-8.

4. Langer P, Kassim RA, Macari GS, et al. Aspergillus infection after total knee arthroplasty. Am J Orthop 2003;32:402-4.

5. Açikgöz ZC, Sayli U, Avci S, et al. An extremely uncommon infection: Candida glabrata arthritis after total knee arthroplasty. Scand J Infect Dis 2002;34:394-6.

6. Baumann PA, Cunningham B, Patel NS, et al. Aspergillus fumigatus infection in a mega prosthetic total knee arthroplasty: Salvage by staged reimplantation with 5-year follow-up. J Arthroplasty 2001;16:498-503.

7. Austin KS, Testa NN, Luntz RK, et al. Aspergillus infection of total knee arthroplasty presenting as a popliteal cyst. Case report and review of the literature. J Arthroplasty 1992;7:311-4.

8. Graw B, Woolson S, Huddleston JI. Candida infection in total knee arthroplasty with successful reimplantation. J Knee Surg 2010;23:169-74.
Laboratory tests and clinical manifestations indicated no adverse reactions. In comparison, Fabry et al (45) reported a case involving C albicans infection of the prosthesis, in which symptoms reappeared two weeks after treatment withdrawal. Thus, there may be a relationship between the duration of the medication and patient recovery after surgery.

Because the patient in the present case refused further surgical treatment, we did not perform a two-stage reimplantation, which was most likely the ideal treatment. In the literature, there are more cases of twostage reimplantation (30 of 91 cases) and removal of the prosthesis (28 of 91 cases) compared with other surgeries. After the prosthesis is removed, instability and dysfunction may occur and, thus, a two-stage reimplantation is recommended. In two reports by Anagnostakos et al (27) and García-Oltra et al (28), the treatment outcomes were drastically different following two-stage reimplantation. In seven two-stage reimplantation cases, Anagnostakos et al (27) reported only one case that did not accept the reoperation, and treatment of the remaining six cases was successful. In contrast, García-Oltra et al (28) reported that only one case was successful following two-stage replantation after debridement, while the remaining six cases failed. In two-stage replacement surgery, the first step involves the removal of the joint prosthesis and insertion of an antibiotic spacer, as well as long-term application of antifungal treatment. Only two single-staged replacement cases have been successful $(6,39)$. In addition, amputation and arthrodesis are becoming rarer because patients do not accept the outcome. Thus, if revision surgery is not possible or if there are contraindications, longterm use of antifungal therapy with retention of the original prosthesis may be an alternative long-term suppression strategy.

\section{CONCLUSION}

Cases of periprosthetic fungal infections after total knee arthoplasty are rare, and the ideal treatment is two-stage revision implantation. However, if the patient's general condition is poor and they are not willing to undergo the revision surgery, long-term treatment with conservative antifungal drugs can be considered on the basis of joint debridement. For immunocompetent patients infected with $T$ asahii, the keys to effective treatment are early detection and long-term application of antifungal treatment.

ACKNOWLEDGEMENTS: The authors thank Medjaden Bioscience Limited for assisting in the preparation of the manuscript.

DISCLOSURES: The authors have no conflicts of interest to declare regarding this article. 
18. Koch AE. Candida albicans infection of a prosthetic knee replacement: A report and review of the literature. J Rheumatol 1988;15:362-5.

19. Wu MH, Hsu KY. Candidal arthritis in revision knee arthroplasty successfully treated with sequential parenteral-oral fluconazole and amphotericin B-loaded cement spacer. Knee Surg Sports Traumatol Arthrosc 2011;19:273-6

20. Springer J, Chatterjee S. Candida albicans prosthetic shoulder joint infection in a patient with rheumatoid arthritis on multidrug therapy. J Clin Rheumatol 2012;18:52-3.

21. Dutronc H, Dauchy FA, Cazanave C, et al. Candida prosthetic infections: Case series and literature review. Scand J Infect Dis 2010;42(11-12):890-5.

22. Kelesidis T, Tsiodras S. Candida albicans prosthetic hip infection in elderly patients: Is flucona zole monotherapy an option? Scand J Infect Dis 2010;42:12-21.

23. Merrer J, Dupont B, Nieszkowska A, et al. Candida albicans prosthetic arthritis treated with fluconazole alone. J Infect 2001;42:208-9

24. Lichtman EA. Candida infection of a prosthetic shoulder joint. Skeletal Radiol 1983;10:176-7.

25. Phelan DM, Osmon DR, Keating MR, et al. Delayed reimplantation arthroplasty for candidal prosthetic joint infection: A report of 4 cases and review of the literature. Clin Infect Dis 2002;34:930-8.

26. Bruce AS, Kerry RM, Norman P, et al. Fluconazole-impregnated beads in the management of fungal infection of prosthetic joints. J Bone Joint Surg Br 2001;83:183-4.

27. Anagnostakos K, Kelm J, Schmitt E, et al. Fungal periprosthetic hip and knee joint infections clinical experience with a 2-stage treatment protocol. J Arthroplasty 2012;27:293-8.

28. García-Oltra E, García-Ramiro S, Martínez JC, et al. Prosthetic joint infection by Candida spp. Rev Esp Quimioter 2011;24:37-41.

29. Johannsson B, Callaghan JJ. Prosthetic hip infection due to Cryptococcus neoformans: Case report. Diagn Microbiol Infect Dis 2009;64:76-9.

30. Lerch K, Kalteis T, Schubert T, et al. Prosthetic joint infections with osteomyelitis due to Candida albicans. Mycoses 2003;46:462-6.

31. Wada M, Baba H, Imura S. Prosthetic knee Candida parapsilosis infection. J Arthroplasty 1998;13:479-82.

32. Fowler VG Jr, Nacinovich FM, Alspaugh JA, et al. Prosthetic joint infection due to Histoplasma capsulatum: Case report and review. Clin Infect Dis 1998;26:1017.

33. Darouiche RO, Hamill RJ, Musher DM, et al. Periprosthetic candidal infections following arthroplasty. Rev Infect Dis 1989;11:89-96.

34. Paul J, White SH, Nicholls KM, et al. Prosthetic joint infection due to Candida parapsilosis in the UK: Case report and literature review. Eur J Clin Microbiol Infect Dis 1992;11:847-9.

35. Gottesman-Yekutieli T, Shwartz O, Edelman A, et al. Pseudallescheria boydii infection of a prosthetic hip joint - an uncommon infection in a rare location. Am J Med Sci 2011;342:250-3.

36. Peel T, Daffy J, Thursky K, et al. Posaconazole as first line treatment for disseminated zygomycosis. Mycoses 2008;51:542-5.

37. Yang SH, Pao JL, Hang YS. Staged reimplantation of total knee arthroplasty after Candida infection. J Arthroplasty 2001;16:529-32.

38. Brooks DH, Pupparo F. Successful salvage of a primary total knee arthroplasty infected with Candida parapsilosis. J Arthroplasty 1998;13:707-12.

39. Selmon GP, Slater RN, Shepperd JA, et al. Successful 1-stage exchange total knee arthroplasty for fungal infection. J Arthroplasty 1998;13:114-5

40. Cushing RD, Fulgenzi WR. Synovial fluid levels of fluconazole in a patient with Candida parapsilosis prosthetic joint infection who had an excellent clinical response. J Arthroplasty 1997;12:950.

41. Lackner M, De Man FH, Eygendaal D, et al. Severe prosthetic joint infection in an immunocompetent male patient due to a therapy refractory Pseudallescheria apiosperma. Mycoses 2011;54 Suppl 3:22-7.

42. Dumaine V, Eyrolle L, Baixench MT, et al. Successful treatment of prosthetic knee Candida glabrata infection with caspofungin combined with flucytosine. Int J Antimicrob Agents 2008;31:398-9.

43. Bland CM, Thomas S. Micafungin plus fluconazole in an infected knee with retained hardware due to Candida albicans.

Ann Pharmacother 2009;43:528-31.
44. Ceffa R, Andreoni S, Borrè S, et al. Mucoraceae infections of antibiotic-loaded cement spacers in the treatment of bacterial infections caused by knee arthroplasty. J Arthroplasty 2002;17:23-8.

45. Fabry K, Verheyden F, Nelen G. Infection of a total knee prosthesis by Candida glabrata: A case report. Acta Orthop Belg 2005;71:119-21.

46. Hennessy MJ. Infection of a total knee arthroplasty by Candida parapsilosis. A case report of successful treatment by joint reimplantation with a literature review. Am J Knee Surg 1996;9:133-6.

47. Levine M, Rehm SJ, Wilde AH. Infection with Candida albicans of a total knee arthroplasty. Case report and review of the literature. Clin Orthop Relat Res 1988;235-9.

48. DeHart DJ. Use of itraconazole for treatment of sporotrichosis involving a knee prosthesis. Clin Infect Dis 1995;21:450.

49. Cutrona AF, Shah M, Himes MS, et al. Rhodotorula minuta: An unusual fungal infection in hip-joint prosthesis. Am J Orthop 2002;31:137-40.

50. MacGregor RR, Schimmer BM, Steinberg ME. Results of combined amphotericin B-5-fluorcytosine therapy for prosthetic knee joint infected with Candida parapsilosis. J Rheumatol 1979;6:451-5.

51. Younkin S, Evarts CM, Steigbigel RT. Candida parapsilosis infection of a total hip-joint replacement: Successful reimplantation after treatment with amphotericin B and 5-fluorocytosine. A case report. J Bone Joint Surg Am 1984;66:142-3.

52. Lejko-Zupanc T, Mozina E, Vrevc F. Caspofungin as treatment for Candida glabrata hip infection. Int J Antimicrob Agents 2005;25:273-4

53. Nayeri F, Cameron R, Chryssanthou E, et al. Candida glabrata prosthesis infection following pyelonephritis and septicaemia. Scand J Infect Dis 1997;29:635-8.

54. Lambertus M, Thordarson D, Goetz MB. Fungal prosthetic arthritis: Presentation of two cases and review of the literature. Rev Infect Dis 1988;10:1038-43.

55. Wyman J, McGough R, Limbird R. Fungal infection of a total knee prosthesis: Successful treatment using articulating cement spacers and staged reimplantation. Orthopedics 2002;25:1391-4.

56. Evans RP, Nelson CL. Staged reimplantation of a total hip prosthesis after infection with Candida albicans. A report of two cases. J Bone Joint Surg Am 1990;72:1551-3.

57. Cardinal E, Braunstein EM, Capello WN, et al. Candida albicans infection of prosthetic joints. Orthopedics 1996;19:247-51.

58. White A, Goetz MB. Candida parapsilosis prosthetic joint infection unresponsive to treatment with fluconazole. Clin Infect Dis 1995;20:1068-9.

59. Lim EV A, Stern PJ. Candida infection after implant arthroplasty. A case report. J Bone Joint Surg Am 1986;68:143-5.

60. Walsh TJ, Melcher GP, Lee JW, et al. Infections due to Trichosporon species: New concepts in mycology, pathogenesis, diagnosis and treatment. Curr Top Med Mycol 1993;5:79-113.

61. Heslop OD, Nyi Nyi MP, Abbott SP, et al. Disseminated trichosporonosis in a burn patient: Meningitis and cerebral abscess due to Trichosporon asahii. J Clin Microbiol 2011;49:4405-8.

62. Rastogi VL, Nirwan PS. Invasive trichosporonosis due to Trichosporon asahii in a non-immunocompromised host: A rare case report. Indian J Med Microbiol 2007;25:59-61.

63. Vazquez JA. Trichosporon infection. Curr Fungal Infect Rep 2010;4:52-8.

64. Badley AD, Van Scoy RE. Long-term follow up of multifocal osteoarticular sporotrichosis treated with itraconazole. Clin Infect Dis 1996;23:394-5.

65. Xia Z, Yang R, Wang W, et al. Genotyping and antifungal drug susceptibility of Trichosporon asahii isolated from Chinese patients. Mycopathologia 2012;173:127-33.

66. Di Bonaventura G, Pompilio A, Picciani C, et al. Biofilm formation by the emerging fungal pathogen Trichosporon asahii: Development, architecture, and antifungal resistance. Antimicrob Agents Chemother 2006;50:3269-76.

67. Pappas PG, Kauffman CA, Andes D, et al. Infectious Diseases Society of America. Clinical practice guidelines for the management of candidiasis: 2009 update by the Infectious Diseases Society of America. Clin Infect Dis 2009;48:503-35. 


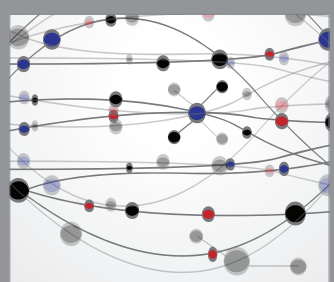

The Scientific World Journal
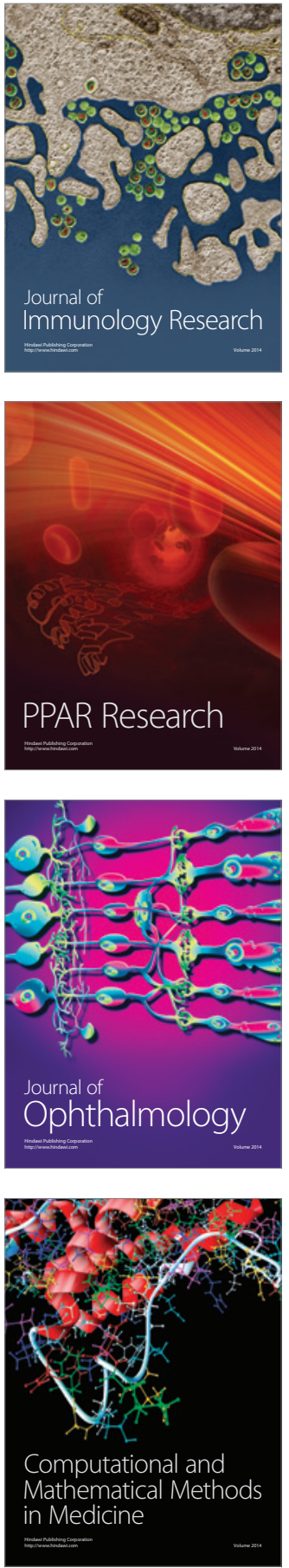

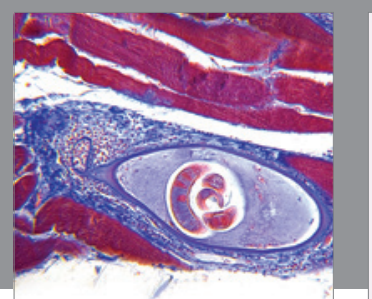

Gastroenterology Research and Practice

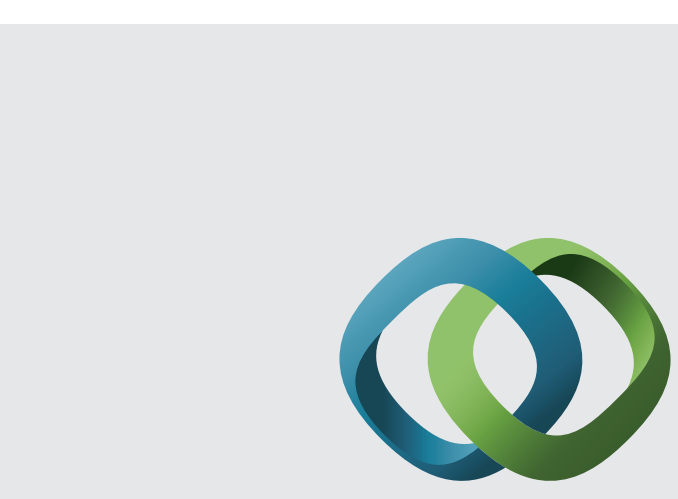

\section{Hindawi}

Submit your manuscripts at

http://www.hindawi.com
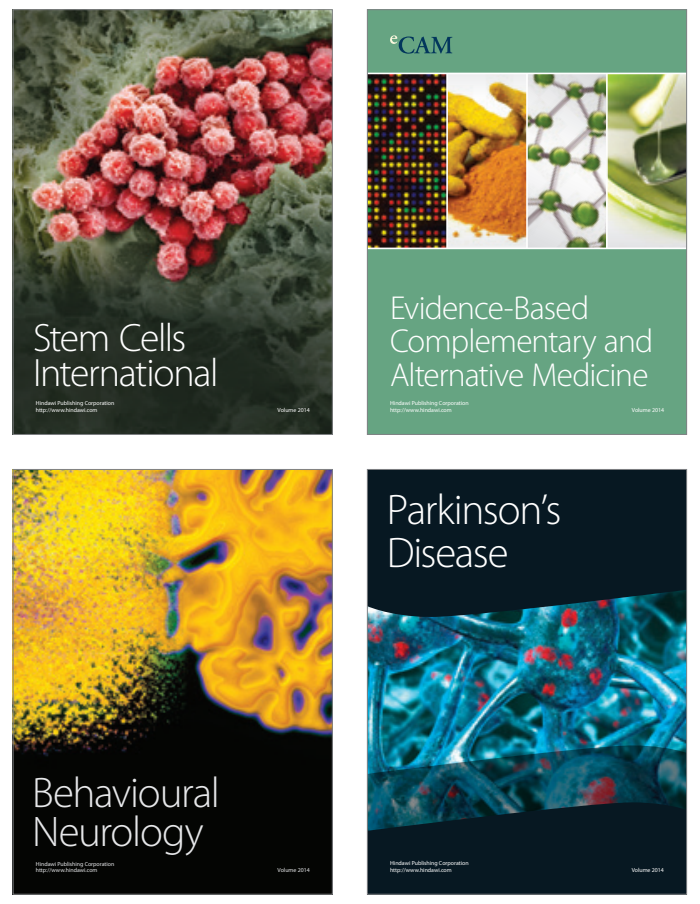
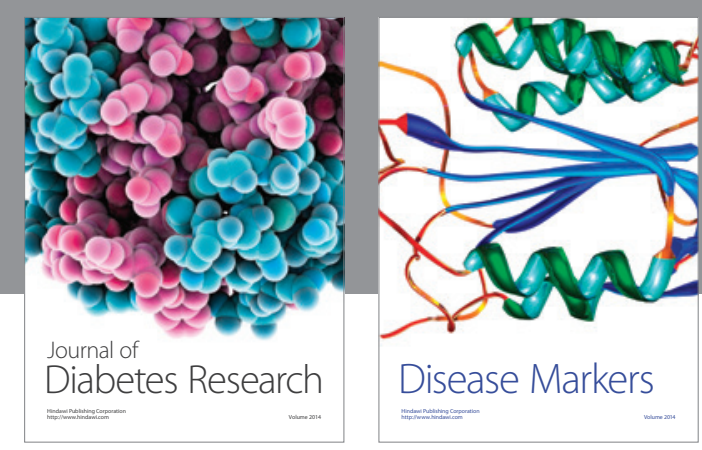

Disease Markers
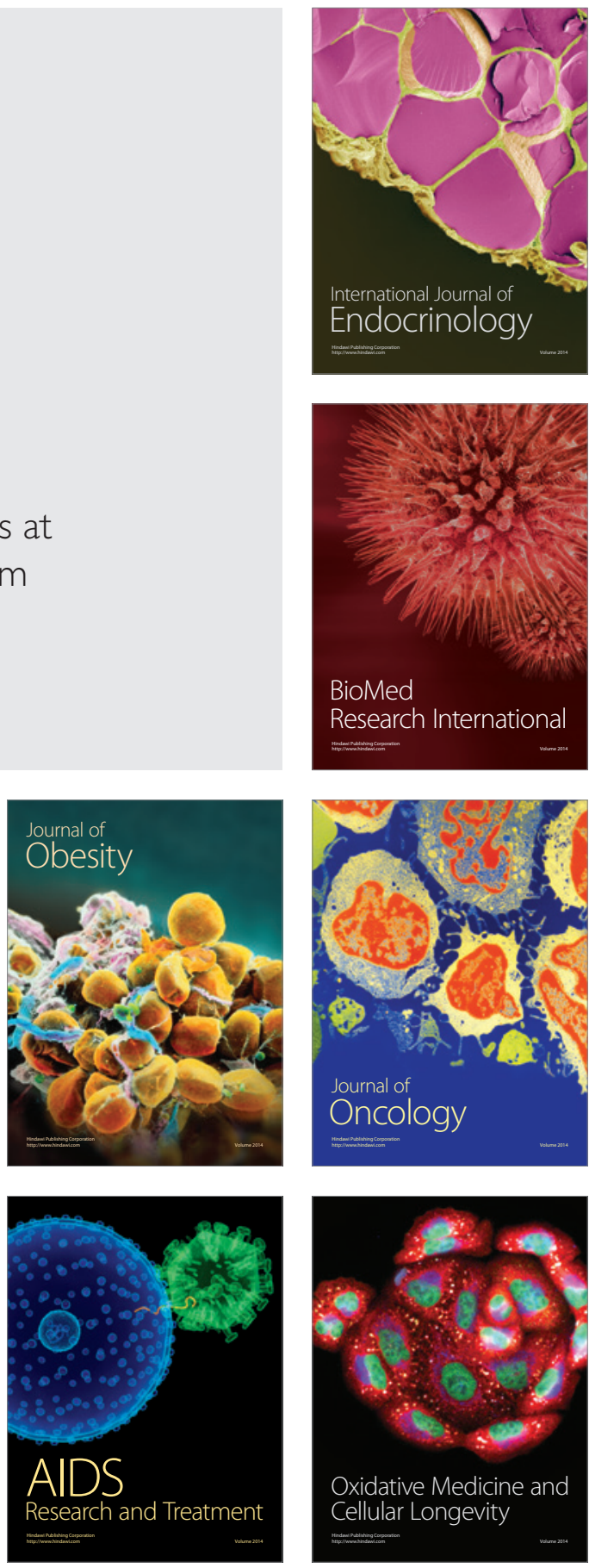